\title{
Simultaneous determinations of fluorine, chlorine, and sulfur in rock samples by ion chromatography combined with pyrohydrolysis
}

\author{
Kenji Shimizu, ${ }^{1,2 *}$ Katsuhiko SuZuki, ${ }^{2}$ MASAfumi Saitoh, ${ }^{3,4}$ Uta Konno, ${ }^{2,5}$ \\ SHINSUKE KAWAGUCCI ${ }^{2,3,5}$ and YUICHIRO $\mathrm{UENO}^{3,4,6}$ \\ ${ }^{1}$ Department of Solid Earth Geochemistry (DSEG), Japan Agency for Marine-Earth Science and Technology (JAMSTEC), \\ 2-15 Natsushima-cho, Yokosuka 237-0061, Japan \\ ${ }^{2}$ Research and Development Center for Submarine Resources, Japan Agency for Marine-Earth Science and Technology (JAMSTEC), \\ 2-15 Natsushima-cho, Yokosuka 237-0061, Japan \\ ${ }^{3}$ Laboratory of Ocean-Earth Life Evolution Research (OELE), Japan Agency for Marine-Earth Science and Technology (JAMSTEC), \\ 2-15 Natsushima-cho, Yokosuka 237-0061, Japan \\ ${ }^{4}$ Department of Earth and Planetary Science, Tokyo Institute of Technology, \\ 2-12-1 Ookayama, Meguro-ku, Tokyo 162-8551, Japan \\ ${ }^{5}$ Department of Subsurface Geobiology Advanced Research (D-SUGAR), Japan Agency for Marine-Earth Science and \\ Technology (JAMSTEC), 2-15 Natsushima-cho, Yokosuka 237-0061, Japan \\ ${ }^{6}$ Earth-Life Science Institute, Tokyo Institute of Technology, 2-12-1 Ookayama, Meguro-ku, Tokyo 162-8551, Japan
}

(Received July 12, 2014; Accepted September 23, 2014)

\begin{abstract}
We present a simplified method for simultaneous determinations of fluorine $(\mathrm{F})$, chlorine $(\mathrm{Cl})$, and sulfur $(\mathrm{S})$ contents and isotopic abundances in rock samples. After using pyrohydrolysis to extract $\mathrm{F}, \mathrm{Cl}$, and $\mathrm{S}$ from a sample and transfer it into a sodium hydroxide $(\mathrm{NaOH})$ solution, concentrations of $\mathrm{F}, \mathrm{Cl}$, and $\mathrm{S}$ as sulfate are measured by ion chromatography. The method is applicable to a variety of rock materials, including peridotite, basalt, gabbro, andesite, rhyolite, sulfide minerals, and possibly to sea salt, with $\mathrm{F}, \mathrm{Cl}$, and $\mathrm{S}$ contents of several $\mu \mathrm{g} \mathrm{g}^{-1}$ to several tens of weight percent in 40 to 250 mg of rock powder. $\mathrm{F}, \mathrm{Cl}$, and $\mathrm{S}$ contents obtained by 5-7 repeated analyses of each of nine geological reference materials were in good agreement with previously reported values. In certain reference materials, sulfite peaks were observed, indicating incomplete oxidation to sulfate during $\mathrm{S}$ extraction by pyrohydrolysis. However, total $\mathrm{S}$ contents in those samples analysed by ICP-AES were also in good agreement with previous reported values. The RSDs of $\mathrm{F}, \mathrm{Cl}$, and $\mathrm{S}$ contents in reference materials were $<6 \%$, except for samples with F content $<10 \mu \mathrm{g} \mathrm{g}^{-1}(\sim 20 \%)$ or S content $<\sim 20 \mu \mathrm{g}$ $\mathrm{g}^{-1}(<20 \%)$. In addition, $\mathrm{Cl}$ isotope compositions of seawater (IAPSO Standard Seawater and Pacific Ocean water) from sample solutions in this study were identical within error to reported values, indicating that $\mathrm{Cl}$ isotopes do not fractionate during pyrohydrolysis. After small isotopic fractionation corrections, multiple isotope compositions of $\mathrm{S}\left({ }^{32} \mathrm{~S},{ }^{33} \mathrm{~S},{ }^{34} \mathrm{~S}\right.$ and ${ }^{36} \mathrm{~S}$ ) in solutions of sulfide (IAEA-S-1, IAEA-S-2, and IAEA-S-3), IAPSO Standard Seawater, and gabbro (JGb-1), also agree well with their respective reported values. Thus, this method is applicable to obtain accurate $\mathrm{Cl}$ and $\mathrm{S}$ contents as well as their isotopic compositions from a single aliquot of sample.
\end{abstract}

Keywords: pyrohydrolysis, halogen, sulfur, ion chromatography, geological reference material

\section{INTRODUCTION}

Concentrations of fluorine $(\mathrm{F})$, chlorine $(\mathrm{Cl})$, and sulfur (S) vary over a wide range in geological samples. Recently F, Cl, and S contents of volcanic samples have become important in research because they behave as volatile elements in magmatic systems, and their relative abundances differ greatly between the Earth's surface and its interior. Therefore, the extent to which hydrothermal

*Corresponding author (e-mail: shimmy@jamstec.go.jp)

Copyright (c) 2015 by The Geochemical Society of Japan. and seawater reactions at the seafloor and degassing processes in a magma chamber have occurred can be precisely evaluated by determining the concentrations of these elements (e.g., Aiuppa et al., 2004; Straub and Layne, 2003; Straub et al., 2004). Moreover, because $S$ can exist as several species, its abundance is important in studies of redox reactions, magma genesis, and ore deposit formation (e.g., Hedenquist and Lowenstern, 1994; Lee et al., 2012).

Bulk data of $\mathrm{F}, \mathrm{Cl}$, and $\mathrm{S}$ in geologic samples are becoming increasingly available but, due to the volatility of these elements and their relatively high contents in environmental blanks, the analytical procedures used pres- 


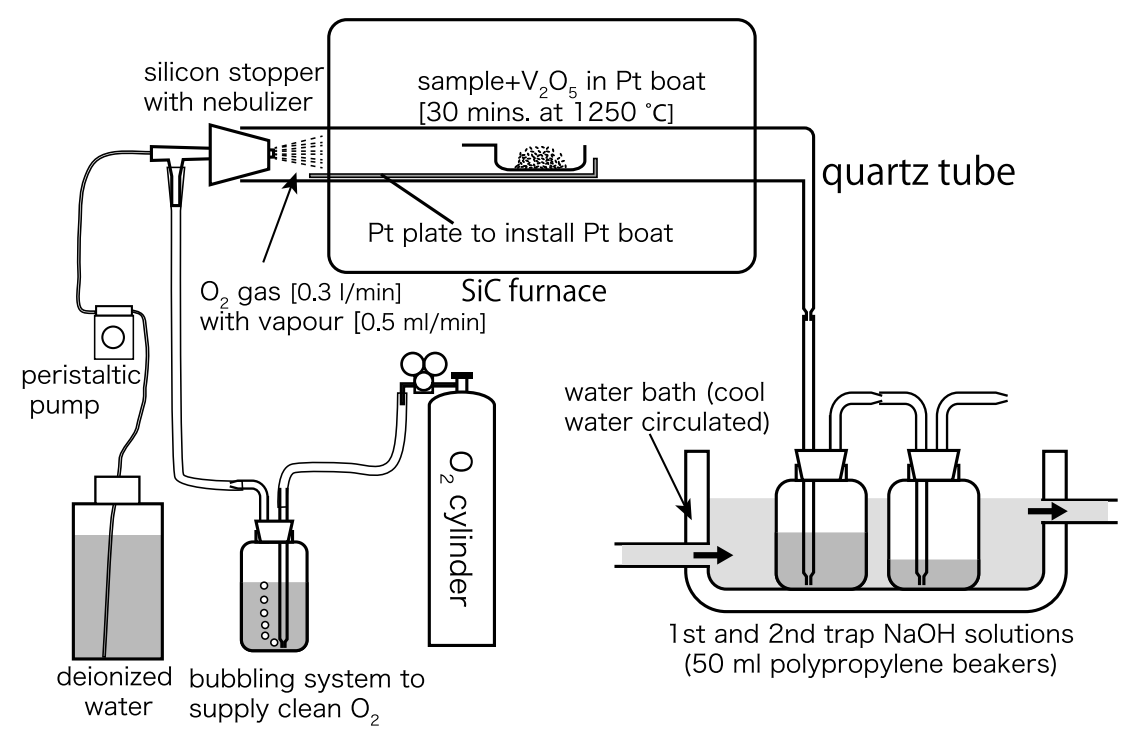

Fig. 1. Schematic illustration of the pyrohydrolysis apparatus used in this study.

ently to determine the $\mathrm{F}, \mathrm{Cl}$, and $\mathrm{S}$ contents of rock samples are complicated and time-consuming, Fluorine and $\mathrm{Cl}$ of bulk rocks are generally extracted by pyrohydrolysis or alkali fusion, and their concentrations are measured by ion chromatography (IC) (Anazawa et al., 2001; Balcone-Boissard et al., 2009; Michel and Villemant, 2003; Shimizu et al., 2006; Wang et al., 2010). However, Wang et al. (2010) demonstrated that part (up to $10 \%$ ) of the $\mathrm{F}$ and $\mathrm{Cl}$ contents could be lost during alkali fusion.

The bulk S content of a sample can be measured by combustion in conjunction with gas mass spectrometry or infrared absorption spectrometry (e.g., Ackerman et al., 2012; Erdman et al., 2014), but large amounts of sample and standard materials whose $\mathrm{S}$ contents are accurately known are required. For smaller samples $(<\sim 0.1$ $\mathrm{g}$ ), powdered rock samples are dissolved in aqua regia and hydrofluoric acid, and then $\mathrm{S}$ is determined by using ICP-MS or ICP-AES (Ackerman et al., 2012; Erdman et al., 2014; Okai et al., 2001). Sulfur is volatile and only slightly soluble in solution under reducing conditions; thus, aqua regia is used to oxidize $\mathrm{S}$ in the sample to sulfate $\left(\mathrm{SO}_{4}{ }^{2-}\right)$, a water-soluble and non-volatile form. However, dissolution of some S-bearing minerals (e.g., barite) may be incomplete, resulting in low recovery of $S$ (Ackerman et al., 2012). Makishima and Nakamura (2001, 2012) dissolved and oxidized rock samples in a S-spiked solution of hydrofluoric and hydrobromic acids and then measured the $\mathrm{S}$ content by isotope dilution high mass resolution ICP-MS. By this method, they could successfully obtain reliable $\mathrm{S}$ concentrations from small amounts of rock sample, but it required an ultra-clean room and the large-scale analytical instrument.
Michel and Villemant (2003) reported a procedure for extraction of $\mathrm{F}, \mathrm{Cl}$, and $\mathrm{S}$ by pyrohydrolysis followed by their simultaneous measurement by IC. However, since their report, no additional S concentrations from geological samples analysed using this method have been reported. In order to increase the database of $\mathrm{S}$ data concurrently measured with $\mathrm{F}$ and $\mathrm{Cl}$ contents by $\mathrm{IC}$, we optimized the pyrohydrolysis extraction procedure and applied the procedure to the extraction of $\mathrm{F}, \mathrm{Cl}$, and $\mathrm{S}$ from geological reference materials, followed by their measurement using IC.

\section{EXPERIMENTAL}

\section{Samples}

We measured $\mathrm{F}, \mathrm{Cl}$, and $\mathrm{S}$ contents of the following geological reference materials: BHVO-2, BCR-2, and BIR-1 (basalt), issued by the U.S. Geological Survey (USGS); and JP-1 (peridotite), JGb-1 (gabbro), JB-2, -3 (basalt), JA-1 (andesite), and JR-1 (rhyolite), issued by the Geological Survey of Japan (GSJ). We also measured the $\mathrm{S}$ content and isotopic compositions of International Atomic Energy Agency (IAEA; Vienna, Austria) silver sulfide standards (IAEA-S-1, IAEA-S-2, and IAEA-S-3) in order to estimate the $\mathrm{S}$ recovery yield and the isotopic fractionation of $\mathrm{S}$ during the pyrohydrolysis procedure. In addition, a seawater standard from the International Association for the Physical Sciences of the Oceans (IAPSO) (supplied by Ocean Scientific International Ltd., UK) and seawater collected from $\sim 6100 \mathrm{~m}$ depth in the Pacific Ocean $\left(11^{\circ} 36^{\prime} \mathrm{N}, 142^{\circ} 59^{\prime} \mathrm{E}\right)$ were evaporated, and then the chlorine content and isotope composition of the seawater-derived salts were measured. 


\section{Pyrohydrolysis}

Fluroine, $\mathrm{Cl}$, and $\mathrm{S}$ were extracted from powdered rock samples by using a pyrohydrolysis technique based on that of Michel and Villemant (2003). The pyrohydrolysis apparatus used in this study (Fig. 1) included a quartz combustion tube, $42 \mathrm{~cm}$ long and $2 \mathrm{~cm}$ in diameter, welded to a quartz collection tube $(\varnothing 6 \mathrm{~mm})$. Before pyrohydrolysis procedure, all quartz and platinum $(\mathrm{Pt})$ components were heated at $1050^{\circ} \mathrm{C}$ for $4 \mathrm{~h}$ in a furnace to remove $\mathrm{F}, \mathrm{Cl}$ and $\mathrm{S}$; other components such as beakers and silicon stoppers were washed with $2 \%$ Tama Super Cleaner (ultrapure strong alkali cleaner, Tama Chemicals Co., Ltd., Japan), and rinsed with deionized water (Milli-Q, >18 M $\Omega$; Millipore, USA). Next, 40-250 mg (normally $100 \mathrm{mg}$ ) of sample powder was weighed in a $\mathrm{Pt}$ boat, and then an appropriate amount of $\mathrm{V}_{2} \mathrm{O}_{5}$ (sample: $\mathrm{V}_{2} \mathrm{O}_{5}$ ratio between $1: 1$ and $1: 3$ ) was weighed and mixed with the sample. In the case of the IAEA-S-1, IAEA-S-2, and IAEA-S-3, 2$5 \mathrm{mg}$ of sample was mixed with $50-60 \mathrm{mg}$ of $\mathrm{V}_{2} \mathrm{O}_{5}$. In the case of the seawater, $\sim 1 \mathrm{~g}$ of seawater was weighed in a $\mathrm{Pt}$ boat. Then, it was dried in an oven at $95^{\circ} \mathrm{C}$ for several hours, and $\sim 50 \mathrm{mg}$ of $\mathrm{V}_{2} \mathrm{O}_{5}$ was added.

In order to place the sample boat at the hottest part of the $\mathrm{SiC}$ furnace (center of $30 \mathrm{~cm}$ long furnace) in high temperature $\left(>800^{\circ} \mathrm{C}\right)$ quickly and safely, we put a Pt boat at the end of a long Pt plate $(15 \mathrm{~cm}$ long $\times 1 \mathrm{~cm}$ wide $)$ and, using tweezers, placed the other end of Pt plate near the edge of combustion tube (Fig. 1). Immediately following the insertion of the Pt plate, the quartz combustion tube was stoppered (within 2-3 seconds) leaving the $\mathrm{Pt}$-plate with a sample boat in the furnace so that no $\mathrm{F}$, $\mathrm{Cl}$, and $\mathrm{S}$ in the sample would escape via the opening. Deionized water mist carried by cleaned $\mathrm{O}_{2}$ gas $(0.31$ $\min ^{-1}$ ) was introduced into the furnace by a peristaltic pump via a nebulizer at the rate of $0.5 \mathrm{ml} \mathrm{min}^{-1}$ in order to collect and transport the $\mathrm{F}, \mathrm{Cl}$, and $\mathrm{S}$ from the sample to the $\mathrm{NaOH}$ solution trap. The initial concentration of the $\mathrm{NaOH}$ solution ranged from 0 (water) to $100 \mathrm{mmol}$ $\mathrm{1}^{-1}$, and the initial volume ranged from 10 to $20 \mathrm{ml}$. The $\mathrm{NaOH}$ solution trap consisted of a $50 \mathrm{ml}$ polypropylene collection beaker resting in an ice-water bath to keep the solution cool. After extraction for $\sim 30 \mathrm{~min}$ at $1200-$ $1250^{\circ} \mathrm{C}$, the tip of the quartz tube was rinsed with deionized water and the rinse water was collected in the same collection beaker. The final volume of the solution collected was $\sim 40 \mathrm{ml}$. Then, the collection beaker was tightly capped for later IC analysis. In order to test the recovery of $\mathrm{F}, \mathrm{Cl}$, and $\mathrm{S}$ in the $\mathrm{NaOH}$ solution, in some experiments we connected a second collection beaker with $\mathrm{NaOH}$ solution to the outlet of the first collection beaker.

After each extraction, the Pt boat and Pt plate were removed and the combustion tube was washed with a deionized water mist at 3-4 $\mathrm{ml} \mathrm{min}^{-1}$ for $\sim 30 \mathrm{~min}$ at $1250^{\circ} \mathrm{C}$. Then, we conducted the next pyrohydrolysis experiment. In order to calculate the weight of the collected solution, the empty collection beaker was weighed before the experiment and again after solution collection had been completed. The weight of the collected solution was derived by subtracting the empty beaker weight from the weight of the beaker with solution. The dilution factor (DF) of sample [total solution weight/sample weight by gram] ranged from 200 to 1000 (usually 500).

\section{Ion chromatography}

In order to measure simultaneously $\mathrm{F}^{-}, \mathrm{Cl}^{-}$, and $\mathrm{SO}_{4}{ }^{2-}$ in the same solution, we used an ICS-2100 IC system (Thermo Scientific, USA) at the Japan Agency for Marine-Earth Science and Technology (JAMSTEC), equipped with an electrolytic eluent generator $(\mathrm{KOH})$ and an ionPac AS11-HC anion exchange column. For effective separation of the $\mathrm{F}^{-}$and $\mathrm{Cl}^{-}$peaks, we used a gradient IC separation script. During each measurement, the concentration of $\mathrm{KOH}$ eluent, which was $6 \mathrm{mmol} \mathrm{l}^{-1}$ at the time of sample injection, was gradually increased to $19 \mathrm{mmol} \mathrm{l}^{-1}$ at $30 \mathrm{~min}$, and then to $45 \mathrm{mmol} \mathrm{l}^{-1}$, where it was maintained for $10 \mathrm{~min}$ to wash out the remaining anions from the exchange column. An electric conductivity detector and an auto-sampler were used in the analysis, and the sample injection loop volume was $100 \mu \mathrm{l}$. Under these analytical conditions, the $\mathrm{F}^{-}, \mathrm{Cl}^{-}$, and $\mathrm{SO}_{4}{ }^{2-}$ peaks generally appeared at $\sim 4.4 \mathrm{~min}, \sim 10.4 \mathrm{~min}$, and $\sim 29.1 \mathrm{~min}$, respectively. Fluorine, $\mathrm{Cl}$, and $\mathrm{S}$ were calibrated against diluted solutions of a commercial standard from Wako Chemicals, Japan. $\mathrm{F}^{-}, \mathrm{Cl}^{-}$, and $\mathrm{SO}_{4}{ }^{2-}$ concentrations of the standard solution were 5, 10, and 40 $\mu \mathrm{g} \mathrm{g}^{-1}$, respectively, and the DF of the solutions used to determine the calibration curves ranged from 5 to 10,000 , which corresponds to 0.5 to $1000 \mathrm{ng} \mathrm{g}^{-1}$ for $\mathrm{F}^{-}, 1$ to 2000 $\mathrm{ng} \mathrm{g^{-1 }}$ for $\mathrm{Cl}^{-}$, and 4 to $8000 \mathrm{ng} \mathrm{g}^{-1}$ for $\mathrm{SO}_{4}{ }^{2-}$. We used two different calibration curves for each anion, depending on the peak intensities. If the peak areas $(\mu \mathrm{S} \cdot \mathrm{min})$ of $\mathrm{F}^{-}, \mathrm{Cl}^{-}$, and $\mathrm{SO}_{4}{ }^{2-}$ in a sample solution were smaller than those of the standard solutions $\left(10,20\right.$, and $80 \mathrm{ng} \mathrm{g}^{-1}$, respectively), we used calibration curves derived from diluted standard solutions with DFs between 500 and 10000. Otherwise, we used calibration curves generated by using diluted standard solutions with DFs from 5 to 500 (Fig. 2). If the peak areas of $\mathrm{F}^{-}, \mathrm{Cl}^{-}$, and $\mathrm{SO}_{4}{ }^{2-}$ of a sample solution exceeded those of standard solutions (1000, 2000, and $8000 \mathrm{ng} \mathrm{g}^{-1}$, respectively), the solution was diluted and remeasured. Reproducibilities of diluted standard solutions with DFs of 10,000 and 5000 were normally better than $\sim 10 \%$ and $\sim 5 \%$, respectively, for $\mathrm{F}$, $\mathrm{Cl}$, and $\mathrm{S}$. Except for blank solutions and solutions in second collection beaker, we were able to use calibration curves for high concentrations to determine $\mathrm{F}, \mathrm{Cl}$ and $\mathrm{S}$ contents of samples. 

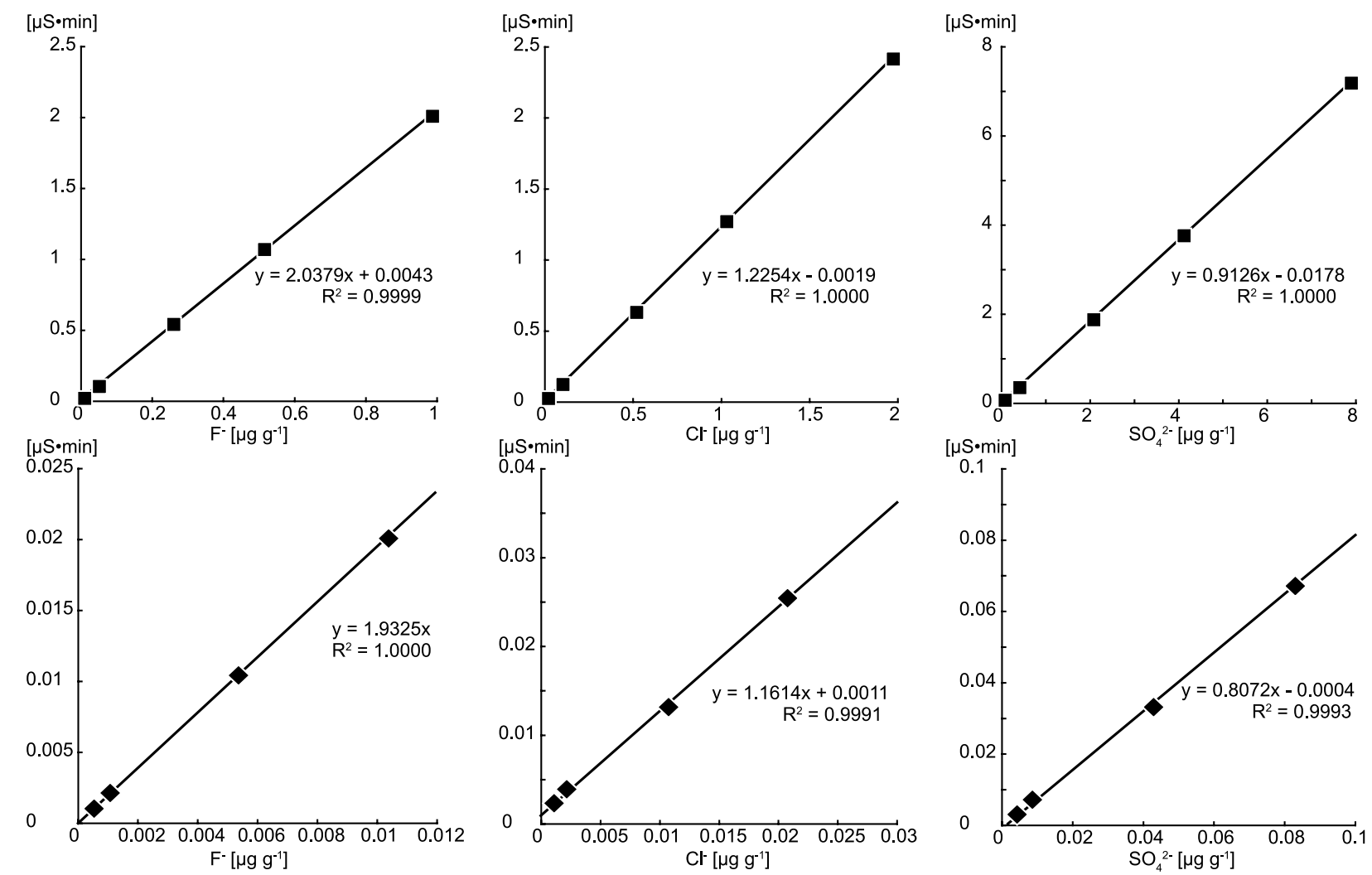

Fig. 2. Calibration curves of $\mathrm{F}^{-}, \mathrm{Cl}^{-}$, and $\mathrm{SO}_{4}{ }^{2-}$ contents used in this study. Upper and lower panels show calibration curves for high and low concentrations respectively.

\section{Procedural blank and $\mathrm{V}_{2} \mathrm{O}_{5}$ reagents}

To estimate a procedural blank for the pyrohydrolysis procedure, we conducted four experiments without any sample or $\mathrm{V}_{2} \mathrm{O}_{5}$ reagent. We confirmed that total procedural blanks for $\mathrm{F}, \mathrm{Cl}$, and $\mathrm{S}$ were $0.01-0.04 \mu \mathrm{g}, 0.07-$ $0.12 \mu \mathrm{g}$, and $0.04-0.08 \mu \mathrm{g}$, respectively. In order to determine which $\mathrm{V}_{2} \mathrm{O}_{5}$ reagent had the lowest blanks, we performed the pyrohydrolysis procedure without rock powder to extract $\mathrm{F}, \mathrm{Cl}$, and $\mathrm{S}$ from $\mathrm{V}_{2} \mathrm{O}_{5}$ reagents purchased from two companies (Alfa Aesar, UK, Aldrich, US). Results are shown in Table 1. All tested $\mathrm{V}_{2} \mathrm{O}_{5}$ reagents contained measureable levels of $\mathrm{F}, \mathrm{Cl}$, and $\mathrm{S}$. Therefore we needed to perform blank corrections to obtain the $\mathrm{F}, \mathrm{Cl}$, and $\mathrm{S}$ contents of unknown samples whenever these reagents were used as catalysts for the pyrohydrolysis procedure. Therefore, we chose $\mathrm{V}_{2} \mathrm{O}_{5}$ Puratronic 99.99\%, purchased from Alfa Aesar, for this study. Although this reagent had a high F content $(23 \mu \mathrm{g}$ $\left.\mathrm{g}^{-1}\right)$, the RSD was small $(\sim 11 \%)$, so the blank correction for $\mathrm{F}$ was effective even when the $\mathrm{F}$ content of the sample was $<\sim 30 \mu \mathrm{g} \mathrm{g}^{-1}$. In addition, after most of our experiments were completed, we tested $99 \% \mathrm{~V}_{2} \mathrm{O}_{5}$ reagents from Wako Chemicals and Kanto Kagaku and found that they had very low contents of $\mathrm{F}, \mathrm{Cl}$, and S (Table 1). We therefore used Kanto Kagaku $99 \% \mathrm{~V}_{2} \mathrm{O}_{5}$ as the catalyst in the pyrohydrolysis of some samples (see Table 2).

\section{$\mathrm{Cl}$ and $\mathrm{S}$ isotope measurements}

The stable isotope composition of chlorine in solution was analysed in the manner previously reported (Long et al., 1993; Wassenaar and Koehler, 2004), with minor modifications. The $\mathrm{Cl}^{-}$solution was first acidified to $\mathrm{pH}$ 1.9 with ultrapure nitric acid $\left(\mathrm{HNO}_{3}\right)$ and then heated at $85^{\circ} \mathrm{C}$ for $45 \mathrm{~min}$ to drive off $\mathrm{CO}_{2}$. Then $1 \mathrm{ml}$ silver nitrate solution $\left(0.5 \mathrm{~mol} \mathrm{l}^{-1} \mathrm{AgNO}_{3}\right)$ was added to precipitate $\mathrm{AgCl}$. The solid $\mathrm{AgCl}$ was collected on a precombusted $0.7 \mu \mathrm{m}$ pore size Whatman glass fibre filter (GF/F). Next the filter was introduced into a glass vial, which was capped with a Teflon-lined butyl gum before evacuation. Fifteen microlitres of liquid iodomethane $\left(\mathrm{CH}_{3} \mathrm{I}\right)$ were injected into the evacuated vial, which was then heated to $80^{\circ} \mathrm{C}$ for $48 \mathrm{~h}$ to quantitatively convert $\mathrm{AgCl}$ to $\mathrm{CH}_{3} \mathrm{Cl}$. The overall $\mathrm{Cl}$ content and abundance of individual stable chlorine isotopes in the $\mathrm{CH}_{3} \mathrm{Cl}$ were determined by continuous-flow isotope ratio mass spectrometry (MAT253, Thermo Finnigan, Bremen, Germany) at JAMSTEC (Konno et al., 2013). The measured chlorine isotope composition is presented by using delta notation 
Table 1. F, $\mathrm{Cl}$ and $\mathrm{S}$ concentrations $\left(\mu \mathrm{g} \mathrm{g}^{-1}\right)$ in $\mathrm{V}_{2} \mathrm{O}_{5}$ regents after procedural blank correction

\begin{tabular}{|c|c|c|c|c|c|c|c|c|c|}
\hline Company & \multicolumn{2}{|c|}{ Grade } & $n$ & $\mathrm{~F}$ & $\mathrm{Cl}$ & $\mathrm{S}$ & F-RSD\% & Cl-RSD\% & S-RSD \% \\
\hline Alfa Aeasar & Puratronic & $99.99 \%$ & 9 & 23 & 0.7 & 0.9 & 11 & 37 & 44 \\
\hline Aldrich & & $99.6 \%$ & 2 & 6.7 & 2.6 & 231 & 1 & 17 & 1 \\
\hline Aldrich & & $99.99 \%$ & 2 & 0.3 & 3.3 & 9.1 & 8 & 3 & 10 \\
\hline Wako Chemicals & & $99 \%$ & 2 & $0 *$ & 0.8 & $0 *$ & - & 1 & - \\
\hline Kanto Kagaku & & $99 \%$ & 4 & 0.2 & 0.3 & 0.1 & 136 & 44 & 31 \\
\hline
\end{tabular}

*Identical to the procedural blank.

on a per mil scale as a following:

$$
\delta^{37} \mathrm{Cl}=\left[\left({ }^{37} \mathrm{Cl} /{ }^{35} \mathrm{Cl}\right)_{\text {sample }} /\left({ }^{37} \mathrm{Cl} /{ }^{35} \mathrm{Cl}\right)_{\mathrm{SMOC}}-1\right] \bullet 1000 \%
$$

where SMOC is Standard Mean Ocean Chloride (Long et $a l ., 1993)$. In practice, chloride in IAPSO seawater was treated as SMOC. For SMOC scaling, we measured the $\delta^{37} \mathrm{Cl}$ value of chloride in the IAPSO seawater, without first precipitating the salt and performing pyrohydrolysis. The standard deviation for the entire procedure was determined to be $0.22 \%$ o $(2 \sigma)$ by repeated measurements of Pacific Ocean water $(n=8)$.

For $\mathrm{S}$ isotope analysis, sulfate in the sample solution was precipitated as $\mathrm{BaSO}_{4}$ by adding $10 \% \mathrm{BaCl}_{2}$ solution after adjusting the $\mathrm{pH}$ to $4-5$. The precipitated $\mathrm{BaSO}_{4}$ was cleaned by repeated centrifuging in deionized water and dried at $70^{\circ} \mathrm{C}$ for $>12 \mathrm{~h}$. The purified $\mathrm{BaSO}_{4}$ was reacted with hot $\operatorname{tin}(\mathrm{II})$ phosphate solution at $300^{\circ} \mathrm{C}$ and converted into $\mathrm{H}_{2} \mathrm{~S}$ (Sasaki et al., 1979; Ueno et al., 2008). The $\mathrm{H}_{2} \mathrm{~S}$ was carried in a nitrogen stream, washed through a water trap, and converted to $\mathrm{Ag}_{2} \mathrm{~S}$ in a centrifuge tube containing a $0.1 \mathrm{~mol}^{-1} \mathrm{AgNO}_{3}$ solution. The $\mathrm{Ag}_{2} \mathrm{~S}$ was then cleaned by repeated centrifuging with distilled water and dried at $70^{\circ} \mathrm{C}$ for $>12 \mathrm{~h}$. The dried $\mathrm{Ag}_{2} \mathrm{~S}$ was reacted with excess $\mathrm{F}_{2}$ at $300^{\circ} \mathrm{C}$ in a nickel reaction vessel overnight to produce $\mathrm{SF}_{6}$. The $\mathrm{SF}_{6}$ was then purified using cryogenic techniques and gas chromatography in a system equipped with a 4 m column packed with Prapack$\mathrm{Q}$ (first) connected to a $2 \mathrm{~m}$ Molecular Sieves 5A column (second). The isotopic composition of the purified $\mathrm{SF}_{6}$ was determined with a ThermoFischer MAT253 mass spectrometer equipped with a dual inlet system at Tokyo Institute of Technology. Sulfur isotopic compositions are reported in conventional delta notation using ViennaCanyon Diablo Troilite (V-CDT) scaling, which is defined by the value of IAEA-S-1 having a composition on the V-CDT scale of $\delta^{34} \mathrm{~S}=-0.300 \%, \Delta^{33} \mathrm{~S}=0.100 \%$, and $\Delta^{36} \mathrm{~S}=-0.91 \%$ (Ding et al., 2001; Ono et al., 2006):

$$
\delta^{x} \mathrm{~S}=\left({ }^{x} R_{\text {sample }} /{ }^{x} R_{\mathrm{VCDT}}-1\right) \cdot 1000 \%
$$

where ${ }^{x} R$ is the isotopic ratio $\left({ }^{x} \mathrm{~S} /{ }^{32} \mathrm{~S}\right.$, where $x=33,34$, or 36) of the sample. For the ${ }^{33} \mathrm{~S} /{ }^{32} \mathrm{~S}$ and ${ }^{36} \mathrm{~S} /{ }^{32} \mathrm{~S}$ ratios, we report $\Delta^{33} \mathrm{~S}$ and $\Delta^{36} \mathrm{~S}$ values defined as follows:

$$
\begin{aligned}
& \Delta^{33} \mathrm{~S} \\
& =1000 \cdot \ln \left(1+\delta^{33} \mathrm{~S} / 1000\right)-0.515 \cdot 1000 \cdot \ln \left(1+\delta^{34} \mathrm{~S} / 1000\right) \%
\end{aligned}
$$

$$
\begin{aligned}
& \Delta^{36} \mathrm{~S} \\
& =1000 \cdot \ln \left(1+\delta^{36} \mathrm{~S} / 1000\right)-1.90 \cdot 1000 \cdot \ln \left(1+\delta^{34} \mathrm{~S} / 1000\right) \%
\end{aligned}
$$

Note that definitions of capital delta $(\Delta)$ values are different from conventional $\delta$ notation $\left(\Delta^{33} \mathrm{~S}=\delta^{33} \mathrm{~S}-\right.$ $\left.1000 \bullet\left(\delta^{34} \mathrm{~S} / 1000+1\right)^{0.515}-1000\right)$, though the difference between the two capital delta values is smaller than $0.1 \%$ o when $\delta^{34} \mathrm{~S}$ varies within $\pm 10 \%$. The analytical reproducibility of $\delta^{34} \mathrm{~S}, \Delta^{33} \mathrm{~S}$, and $\Delta^{36} \mathrm{~S}$ values determined by replicate analyses of IAEA-S-1 were $0.43 \%$, $0.015 \%$, and $0.16 \%$ o $(1 \sigma)$, respectively $(n=7)$.

\section{RESUlTS AND DisCUSSION}

\section{Optimizing pyrohydrolysis conditions}

There are many parameters to optimize pyrohydrolysis conditions that may affect recovery yields of $\mathrm{F}, \mathrm{Cl}$ and $\mathrm{S}$, including the sample amount, kind of oxidizing catalyst $\left(\mathrm{V}_{2} \mathrm{O}_{5}\right.$ or $\left.\mathrm{WO}_{3}\right)$, sample/catalyst ratios, flow rates of carrier gas and water mist, temperature, duration, sample insertion temperature, and the initial concentration and volume of $\mathrm{NaOH}$ solution in the collection beaker. Based on the results of previous works (Balcone-Boissard et al., 2009; Michel and Villemant, 2003; Wang et al., 2010), the initial concentration and volume of $\mathrm{NaOH}$ solution in the collection beaker and sample insertion temperature are not well-constrained effective parameters for the recovery yields. Therefore, we conducted the pyrohydrolysis experiments with BHVO-2 under various volumes and concentrations of initial $\mathrm{NaOH}$ solutions and sample insertion temperatures to optimize the condition (Table 2). Under all experimental conditions, concentrations of $\mathrm{F}$ and $\mathrm{Cl}$ derived from the sample solution of the second beaker were negligible, indicating that $\sim 100 \%$ entrapment of $\mathrm{F}^{-}$and $\mathrm{Cl}^{-}$in the sample solution in the first beaker was achieved. $\mathrm{F}$ (and $\mathrm{Cl}$ ) concentrations of BHVO-2 after blank correction were identical regardless of the insertion temperature and the $\mathrm{NaOH}$ solution con- 


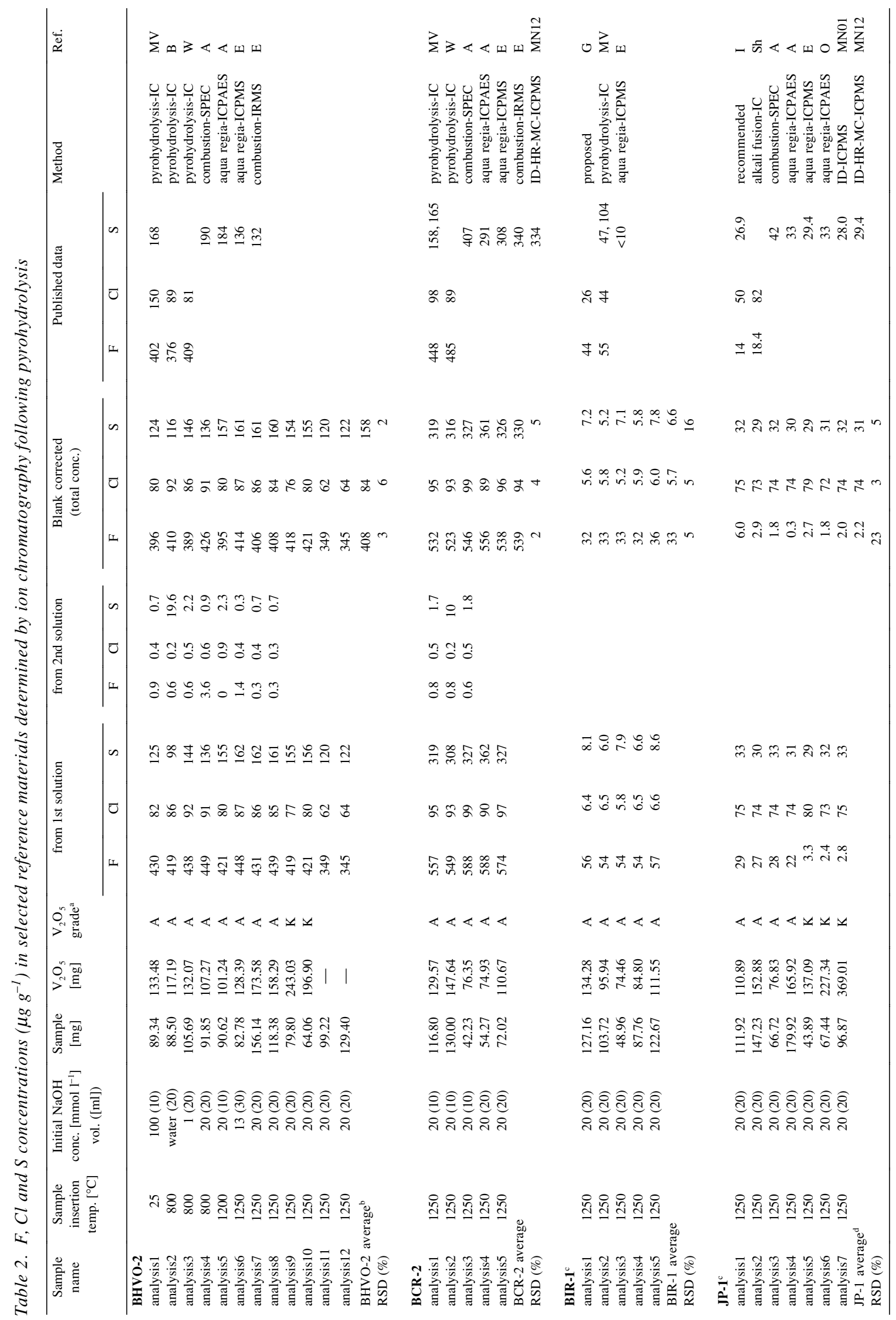




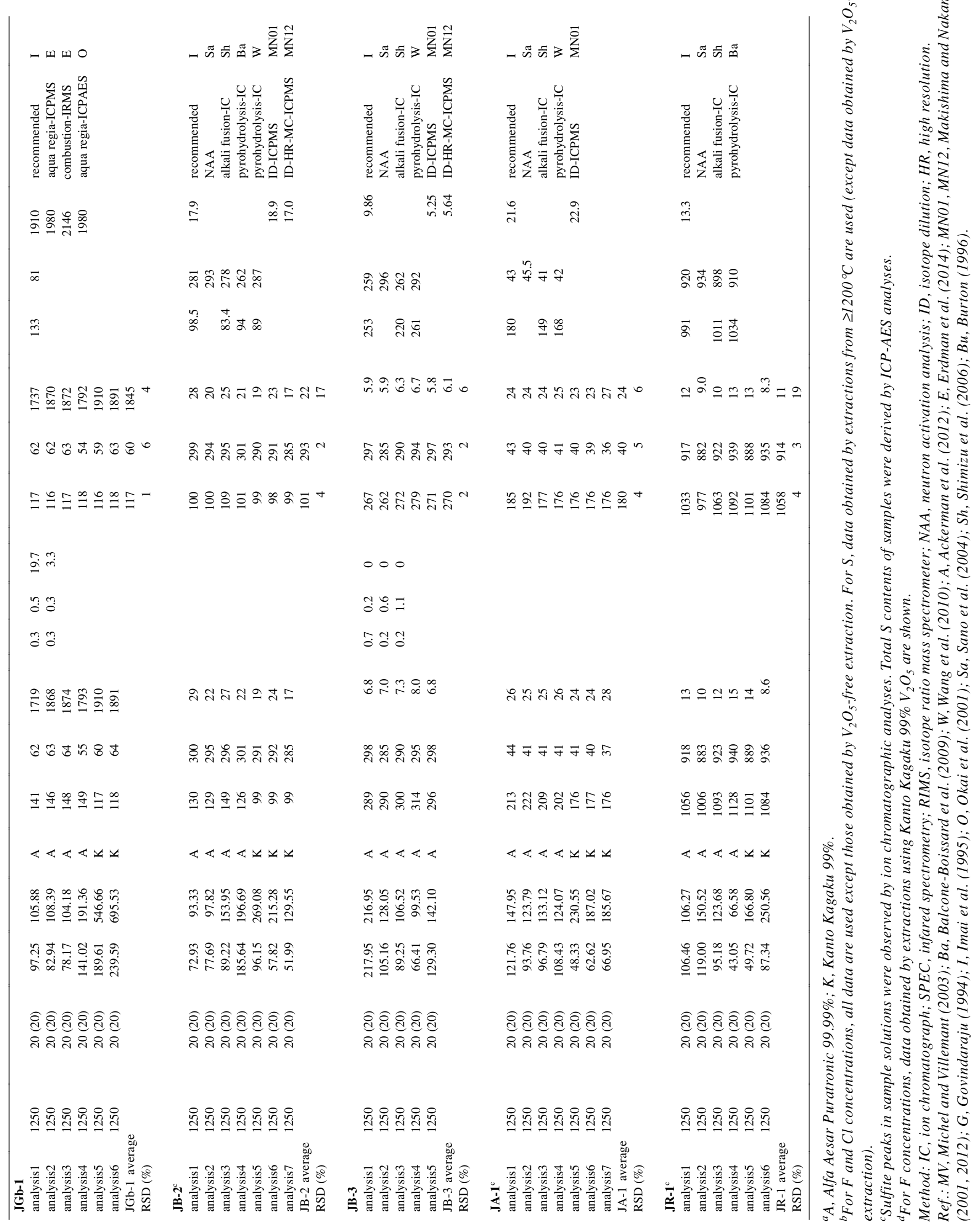




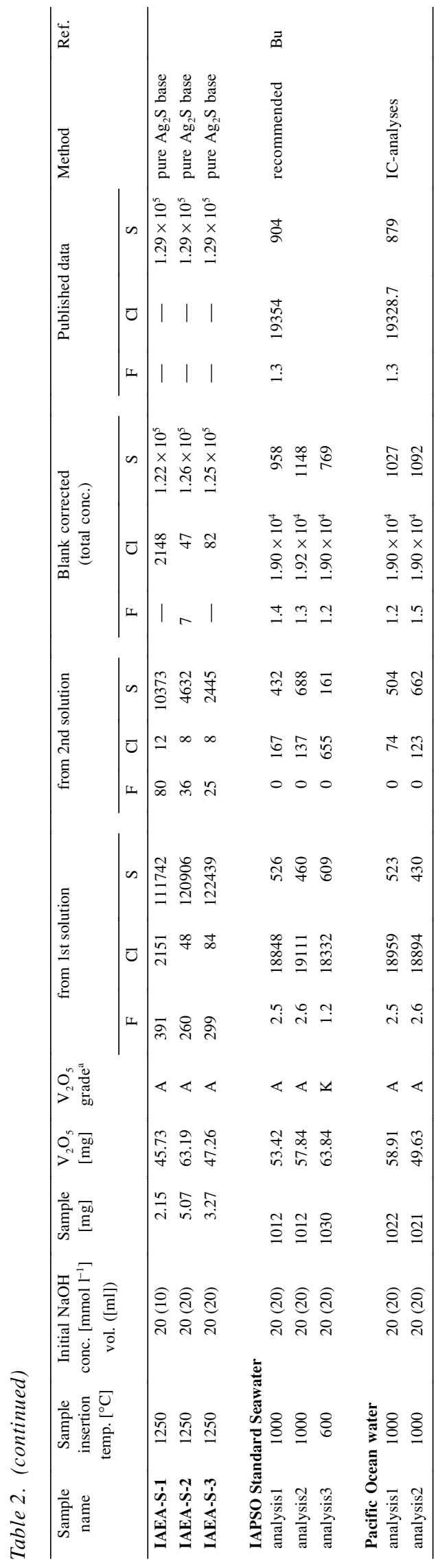

centration and volume, and are in good agreement with published values. Concentrations of $\mathrm{S}$ derived from the sample solutions of the second beaker were also negligible for many conditions. However, when the initial volume of the $\mathrm{NaOH}$ solution was $10 \mathrm{ml}$ and its concentration was $<1 \mathrm{mmol} \mathrm{l}^{-1}$, entrapment of $\mathrm{S}$ in the sample solution of the first beaker was $<99 \%$. In particular, not all $\mathrm{S}$ extracted by pyrohydrolysis may be trapped in pure water (Table 2, BHVO-2 analysis2). Blank-corrected S concentrations in BHVO-2 obtained by sample insertion at room temperature and $800^{\circ} \mathrm{C}$ (BHVO-2 analysis1-4) were $\sim 15 \%$ lower than those obtained by sample insertion at $1200^{\circ} \mathrm{C}$ or $1250^{\circ} \mathrm{C}$ (BHVO-2 analysis5-9). Because the melting temperature of $\mathrm{V}_{2} \mathrm{O}_{5}$ is $690^{\circ} \mathrm{C}, \mathrm{V}_{2} \mathrm{O}_{5}$ melts before the $\mathrm{S}$ is extracted from a sample. As a result, it may not efficiently catalyse the oxidation of $\mathrm{S}$ to $\mathrm{SO}_{3}$. Therefore, some $\mathrm{S}$ in the sample may escape as slightly soluble and volatile $\mathrm{H}_{2} \mathrm{~S}$ or remain in a sample residue as sulfide. Our experimental results indicate that the initial concentration and volume of the $\mathrm{NaOH}$ solution should be $20 \mathrm{mmol} \mathrm{l}^{-1}$ and $20 \mathrm{ml}$, respectively, and that the temperature at sample insertion should be as high as the heating temperature $\left(1250^{\circ} \mathrm{C}\right)$, but a second collection beaker is not necessary for a low-S sample.

We extracted $\mathrm{S}$ from $\mathrm{Ag}_{2} \mathrm{~S}$ (IAEA-S-1, IAEA-S-2, and IAEA-S-3) under the appropriate conditions and confirmed the high recovery (94-97\%) of S and the complete oxidation of sulfide to sulfate (Table 2). However, $\mathrm{S}$ leakage to the second collection beaker was significantly high when the volume of the initial $\mathrm{NaOH}$ solution was $10 \mathrm{ml}$ (IAEA-S-1). The $\mathrm{S}$ content in the sample solutions of the second beaker was also not negligible even when the volume of the initial $\mathrm{NaOH}$ solution was $20 \mathrm{ml}$. Therefore, for high-S samples, a second collection beaker and a higher concentration $\mathrm{NaOH}$ solution may be required. We confirmed that $\mathrm{Cl}$ recovery from seawater (salt) using the pyrohydrolysis procedure was from 98.1 to $99.5 \%$ (Table 2). This result shows that the method is also applicable to samples with extremely high $\mathrm{Cl}$.

In addition, we conducted pyrohydrolysis experiments with BHVO-2 without any $\mathrm{V}_{2} \mathrm{O}_{5}$ reagent (Table 2, BHVO2 analysis 11, 12). The obtained $\mathrm{F}, \mathrm{Cl}$, and $\mathrm{S}$ contents were all $\sim 20 \%$ lower than those obtained by extraction with the $\mathrm{V}_{2} \mathrm{O}_{5}$ reagent, thus confirming that $\mathrm{V}_{2} \mathrm{O}_{5}$ is required to extract $\mathrm{F}, \mathrm{Cl}$, and $\mathrm{S}$ by pyrohydrolysis. The sample: $\mathrm{V}_{2} \mathrm{O}_{5}$ ratio in the pyrohydrolysis procedure does not affect recovery of $\mathrm{F}, \mathrm{Cl}$, and $\mathrm{S}$ as long as the sample: $\mathrm{V}_{2} \mathrm{O}_{5}$ ratio is between $1: 1$ and $1: 3$.

\section{$F, C l$, and $S$ contents of reference materials}

We conducted five to seven repeat analyses of each reference material and averaged the values to obtain their $\mathrm{F}, \mathrm{Cl}$, and $\mathrm{S}$ concentrations (Table 2, Fig. 4). The F content of JP-1 was very low and, subsequently, the data ob- 

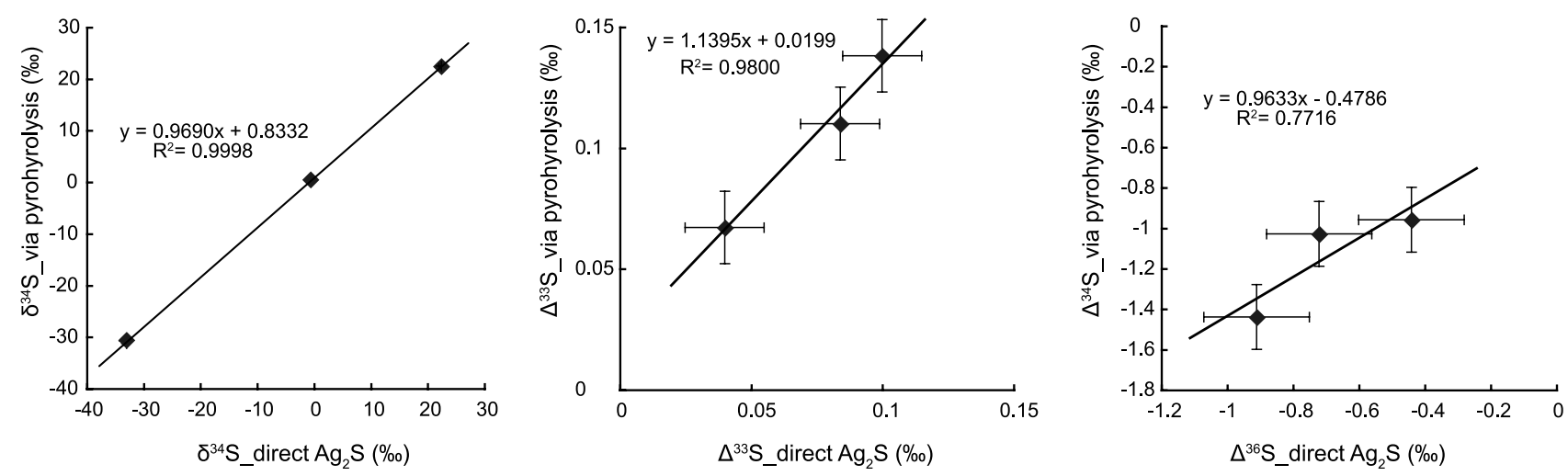

Fig. 3. Correlations of multiple sulfur isotopic compositions for IAEA-S-1, IAEA-S-2 and IAEA-S-3 obtained by direct $\mathrm{Ag}_{2} \mathrm{~S}$ fluorinations vs. sulfate sample solutions via pyrohydrolysis.
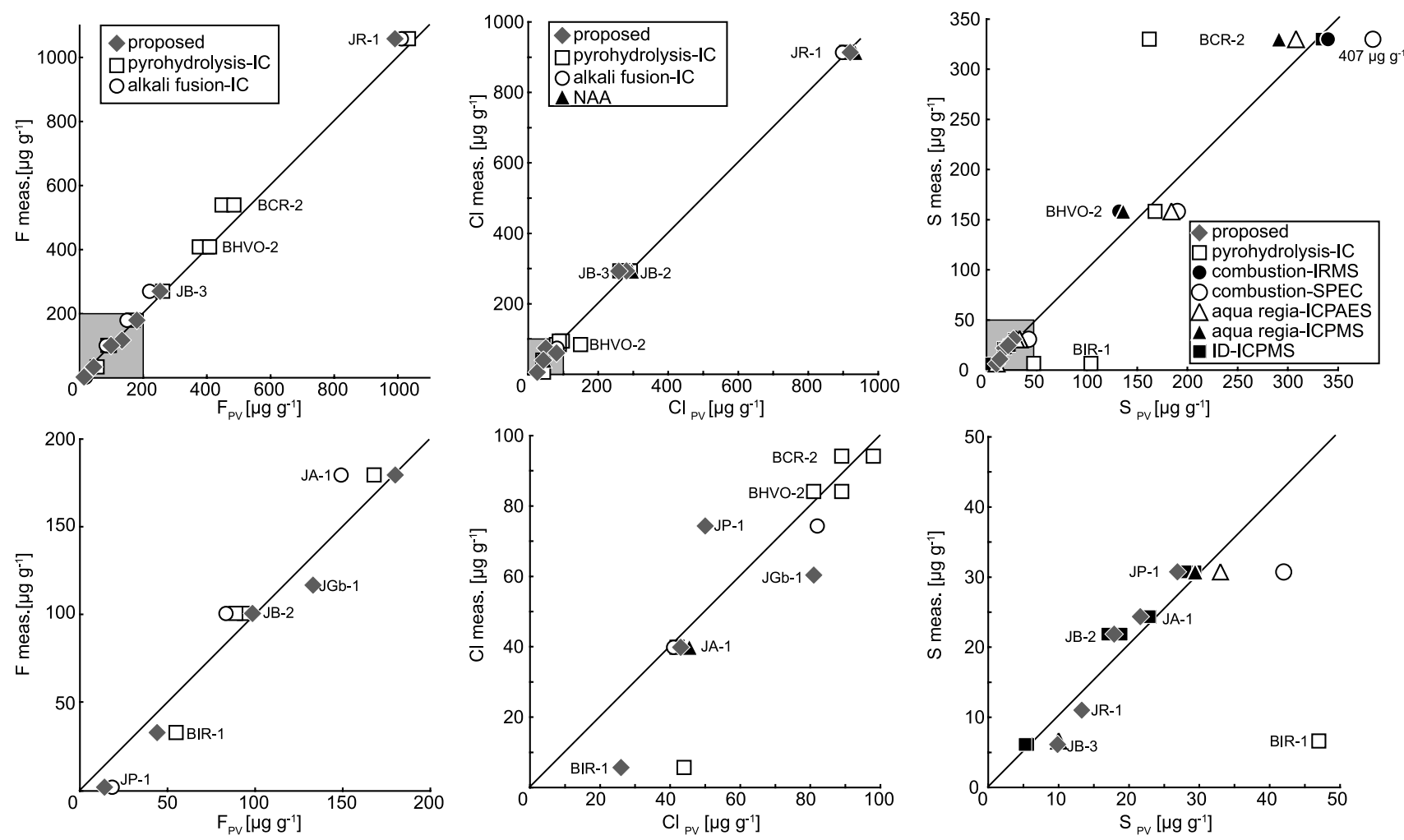

Fig. 4. Mean measured values (this study) of $F, C l$ and $S$ concentrations compared with published values (PV). Lower panels are close-up diagrams of upper panel diagrams indicated as shaded squares. Sulfur concentrations of JGb-1 are out of range of the shown diagram $\left(S \sim 2000 \mu \mathrm{g} \mathrm{g}^{-1}\right)$. References for published values with methods are listed in Table 2.

tained using the Alfa Aesar $\mathrm{V}_{2} \mathrm{O}_{5}$ extraction catalyst (Table 2, JP-1 anaylysis1-4) required a large blank correction $(>1000 \%)$. Therefore, we used data obtained using the Kanto Kagaku reagent (JP-1 anaylysis5-7) for the F content of JP-1.

In certain sample solutions (BIR-1, JP-1, JB-2, JA-1, and JR-1), sulfite $\left(\mathrm{SO}_{3}{ }^{2-}\right)$ peaks were identified by IC, indicating that $\mathrm{S}$ was not completely oxidized to sulfate during the pyrohydrolysis procedure. Therefore, we analysed total S contents of these samples by ICP-AES equipped with a semiconducting detector and pure nitrogen purging of the spectrometer optics (SPS5500, SII Nano Technology, Chiba, Japan). Two emission wavelengths can be used to measure $\mathrm{S}$ content $(180.669 \mathrm{~nm}$ or 


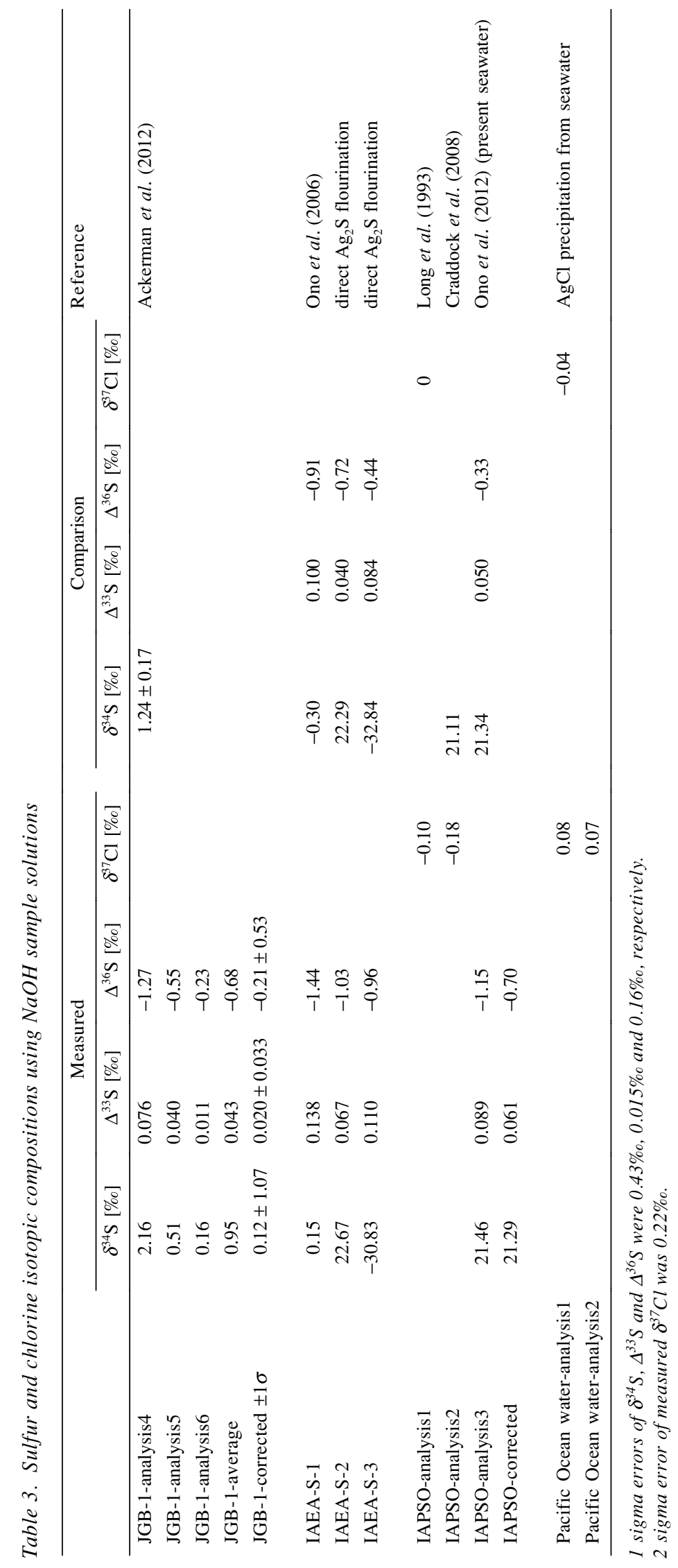


$181.972 \mathrm{~nm}$ ) by an ICP-AES system. We used the 181.972 $\mathrm{nm}$ line because the sensitivity, reproducibility, and linearity of the calibration curve for $\mathrm{S}$ at the $181.972 \mathrm{~nm}$ line were slightly better than those at the $180.669 \mathrm{~nm}$ line. The detection limit of $S$ in solution at $181.972 \mathrm{~nm}$ was 10 $\mathrm{ng} \mathrm{g}^{-1}$, as calculated from the $3 \sigma$ value of the instrumental background. This value corresponds to $5 \mu \mathrm{g} \mathrm{g}^{-1}$ of $\mathrm{S}$ in a sample for the usual sample DF ( 500) used in this study. The RSD of each measurement near the detection limit was $15 \%$ and was derived by repeated analyses of a $\sim 10 \mathrm{ng} \mathrm{g}^{-1}$ solution.

In most cases, the RSD of the $\mathrm{F}, \mathrm{Cl}$, and $\mathrm{S}$ contents of reference materials was $<6 \%$, indicating that the reference materials were relatively homogeneous among the distributed portions. The large uncertainty in the F content of JP-1 (RSD, 23\%) can be explained by the relatively large blank correction (up to $35 \%$ ). Although the S contents of BIR-1, JB-2, and JR-1 had relatively large uncertainty (up to $20 \%$ ), the data were close to the ICPAES detection limit; therefore, these large uncertainties are inevitable.

The $\mathrm{F}, \mathrm{Cl}$, and $\mathrm{S}$ contents of most of the reference materials were in relatively good agreement with previously reported values (Table 2, Fig. 4). However, reported $\mathrm{F}, \mathrm{Cl}$, and S contents of BIR-1 and the F contents of BCR2 and JP-1 are clearly different from values determined in this study. Even so, there are so few reported values that it is difficult to judge whether or not they are reliable. The distributed test portions of the reference materials might also be heterogeneous, as described by Erdman et al. (2014). Systematically lower $\mathrm{F}$ and $\mathrm{Cl}$ contents of certain reference materials (i.e., JB-2, JB-3, and JA-1) extracted by alkali fusion (Shimizu et al., 2006) may indicate $\mathrm{F}$ and $\mathrm{Cl}$ loss during extraction, as demonstrated by Wang et al. (2010).

\section{$\mathrm{Cl}$ and $\mathrm{S}$ isotopic compositions}

The $\mathrm{Cl}$ isotope compositions of seawater-derived salts (from IAPSO Standard Seawater and Pacific Ocean water) were analysed after extraction by pyrohydrolysis (Table 3). The $\delta^{37} \mathrm{Cl}$ values scaled by the IAPSO Standard Seawater analysis were identical within the analytical error between the salts derived from the IAPSO $(-0.18 \%)$ and the Pacific Ocean water $(+0.07 \%)$.

The $\mathrm{S}$ isotopic compositions of the sulfide (IAEA-S1, IAEA-S-2, and IAEA-S-3) and gabbro (JGb-1) sample solutions were measured (Table 3 ). Before the $\mathrm{S}$ isotope measurements of IAEA-S-1, IAEA-S-2, IAEA-S-3 and IAPSO Standard Seawater, the solutions in the first and second collection beakers were combined into one beaker in order to determine the $\mathrm{S}$ isotope composition of the total extracted S. We only analysed the S isotopic composition for IAPSO-analysis3, because for the other seawater measurements, a substantial amount of $S$ escaped to the second beaker (Table 2), indicating incomplete recovery of $\mathrm{S}$ from seawater. The higher $\mathrm{S}$ contents of seawater extracted with pyrohydrolysis (S: 958-1148 $\mu \mathrm{g}$ $\mathrm{g}^{-1}$ ) compared with that measured without pyrohydrolysis (S: 879 or $904 \mu \mathrm{g} \mathrm{g}^{-1}$ ) may indicate a degree of S contamination during the evaporation process. The various $S$ isotope compositions for IAEA-S-1, IAEA-S-2 and IAEA$\mathrm{S}-3$ are slightly different from those measured by the direct $\mathrm{Ag}_{2} \mathrm{~S}$ fluorinations, but were linearly correlated (Fig. 3 ). Therefore the actual isotope compositions can be obtained using a mass fractionation correction. Although analysis 3 of IAPSO Standard Seawater had $\sim 15 \%$ lower $\mathrm{S}$ content than expected (Table 2), its corrected $\delta^{34} \mathrm{~S}, \Delta^{33} \mathrm{~S}$, $\Delta^{36} \mathrm{~S}$ values were identical within the analytical error to reported values of IAPSO Standard Seawater (e.g., Craddock et al., 2008) and present seawater (e.g., Ono et al., 2012). Reproducibilities of $\delta^{34} \mathrm{~S}, \Delta^{33} \mathrm{~S}$, and $\Delta^{36} \mathrm{~S}$ for JGb-1 were significantly larger than those for the standard, IAEA-S-1. Although it is uncertain whether JGb-1 is heterogeneous in terms of $S$ isotopes or if a larger than expected $\mathrm{S}$ isotope fractionation occurred during extraction or reduction processes, $\delta^{34} \mathrm{~S}$ value of JGb-1 is still within analytical error of the range of reported values (Ackerman et al., 2012).

These results indicate that $\mathrm{Cl}$ isotopic compositions do not fractionate during pyrohydrolysis and that the multiple $\mathrm{S}$ isotopic compositions can be obtained using small isotope fractionation corrections. Therefore, this extraction method can be used to obtain accurate $\mathrm{Cl}$ and $\mathrm{S}$ contents as well as their isotopic composition from a single aliquot of sample.

\section{CONCLUSions}

We established a simple method for determining F, $\mathrm{Cl}$, and $\mathrm{S}$ in small (as little as $40 \mathrm{mg}$ ) rock samples by using IC after pyrohydrolysis extraction. We determined their contents in reference materials ranging from peridotite to rhyolite containing $\mathrm{F}, \mathrm{Cl}$, and $\mathrm{S}$ contents ranging from $<10 \mu \mathrm{g} \mathrm{g}^{-1}$ to $>1000 \mu \mathrm{g} \mathrm{g}^{-1}$ and achieved analytical results in good agreement with values reported in the literatures. We were also able to determine the $\mathrm{Cl}$ and $\mathrm{S}$ isotope compositions of sample solutions obtained by the pyrohydrolysis procedure.

Acknowledgments-We thank C. Toyama and Y. Muramatsu in Gakushuin University for discussions. We also thank W. Nelson in University of Houston for improving the manuscript. Analytical support by H. Makita and S. Kubo is acknowledged. Reviews by T. Maruoka and an anonymous reviewer and editorial comments by $\mathrm{T}$. Matsumoto are appreciated. This work was financially supported by grants from the Japan Society for the Promotion of Science (No. 23740381 and No. 25610160 to Shimizu, No. 20109006 to Suzuki), a JAMSTEC Houga Award to Kawagucci and the NEXT program (GR033) to Ueno and Saitoh. 


\section{REFERENCES}

Ackerman, L., Rohovec, J. and Sebek, O. (2012) Determination of total sulfur in fifteen geological materials using Inductively Coupled Plasma-Optical Emission Spectrometry (ICP-OES) and combustion/infrared spectrometry. Geostand. Geoanal. Res. 36, 407-414.

Aiuppa, A., Federico, C., Giudice, G., Gurrieri, S., Paonita, A. and Valenza, M. (2004) Plume chemistry provides insights into mechanisms of sulfur and halogen degassing in basaltic volcanoes. Earth Planet. Sci. Lett. 222, 469-483.

Anazawa, K., Tomiyasu, T. and Sakamoto, H. (2001) Simultaneous determination of fluorine and chlorine in rocks by ion chromatography in combination with alkali fusion and cation-exchange pretreatment. Anal. Sci. 17, 217-219.

Balcone-Boissard, H., Michel, A. and Villemant, B. (2009) Simultaneous determination of fluorine, chlorine, bromine and iodine in six geochemical reference materials using pyrohydrolysis, ion chromatography and inductively coupled plasma-mass spectrometry. Geostand. Geoanal. Res. 33, 477-485.

Burton, J. D. (1996) The Ocean: a global chemical system. Oceanography an Illustrated Guide (Summerhayes, C. P. and Thorpe, S. A., eds.), 165-181, John Wiley.

Craddock, P. R., Rouxel, O. J., Ball, L. A. and Bach, W. (2008) Sulfur isotope measurement of sulfate and sulfide by highresolution MC-ICP-MS. Chem. Geol. 253, 102-113.

Ding, T., Valkiers, S., Kipphardt, H., De Bievre, P., Taylor, P. D. P., Gonfiantini, R. and Krouse, R. (2001) Calibrated sulfur isotope abundance ratios of three IAEA sulfur isotope reference materials and V-CDT with a reassessment of the atomic weight of sulfur. Geochim. Cosmochim. Acta $\mathbf{6 5}$, 2433-2437.

Erdman, M. E., Lee, C. T. A., Yang, W. and Ingram, L. (2014) Sulfur concentration in geochemical reference materials by solution inductively coupled plasma-mass spectrometry. Geostand. Geoanal. Res. 38, 51-60.

Govindaraju, K. (1994) 1994 complication of working values and sample description for 383 geostandards. Geostand. Newsl. 18 (Special Issue), 158.

Hedenquist, J. W. and Lowenstern, J. B. (1994) The role of magmas in the formation of hydrothermal ore-deposits. Nature 370, 519-527.

Imai, N., Terashima, S., Itoh, S. and Ando, A. (1995) 1994 compilation of analytical data for minor and trace-elements in seventeen GSJ geochemical reference samples, igneous rock series. Geostand. Newsl. 19, 135-213.

Konno, U., Takai, K. and Kawagucci, S. (2013) Stable chlorine isotope ratio analysis of subnanomolar level methyl chloride by continuous-flow isotope ratio mass spectrometry. Geochem. J. 47, 469-473.

Lee, C. T. A., Luffi, P., Chin, E. J., Bouchet, R., Dasgupta, R., Morton, D. M., Le Roux, V., Yin, Q. Z. and Jin, D. (2012) Copper systematics in arc magmas and implications for crust-mantle differentiation. Science 336, 64-68.

Long, A., Eastoe, C. J., Kaufmann, R. S., Martin, J. G., Wirt, L. and Finley, J. B. (1993) High-precision measurement of chlorine stable-isotope ratios. Geochim. Cosmochim. Acta 57, 2907-2912.
Makishima, A. and Nakamura, E. (2001) Determination of total sulfur at microgram per gram levels in geological materials by oxidation of sulfur into sulfate with in situ generation of bromine using isotope dilution high resolution ICPMS. Anal. Chem. 73, 2547-2553.

Makishima, A. and Nakamura, E. (2012) High-resolution MCICPMS employing amplifiers with a 10 (12) ohm resistor for bulk sulfur determination in biological and geological samples. J. Anal. Atom. Spectrom. 27, 891-895.

Michel, A. and Villemant, B. (2003) Determination of halogens $(\mathrm{F}, \mathrm{Cl}, \mathrm{Br}, \mathrm{I})$, sulfur and water in seventeen geological reference materials. Geostand. Newsl. 27, 163-171.

Okai, T., Terashima, S. and Imai, N. (2001) Determination of total sulfur in thirty one geochemical reference materials using an inductively coupled plasma-atomic emission spectrometer fitted with a semiconductor photodiode detector. Geostand. Newsl. 25, 133-136.

Ono, S., Wing, B., Johnston, D., Farquhar, J. and Rumble, D. (2006) Mass-dependent fractionation of quadruple stable sulfur isotope system as a new tracer of sulfur biogeochemical cycles. Geochim. Cosmochim. Acta 70, 2238-2252.

Ono, S. H., Keller, N. S., Rouxel, O. and Alt, J. C. (2012) Sulfur33 constraints on the origin of secondary pyrite in altered oceanic basement. Geochim. Cosmochim. Acta 87, 323-340.

Sano, T., Fukuoka, T. and Hasenaka, T. (2004) Determination of chlorine contents in geological survey of Japan reference materials by prompt gamma neutron activation analysis. Geostand. Geoanal. Res. 28, 443-448.

Sasaki, A., Arikawa, Y. and Folinsbee, R. E. (1979) Kiba reagent method of sulfur extraction applid to isotopic work. Bull. Geol. Surv. Japan 30, 241-245.

Shimizu, K., Itai, T. and Kusakabe, M. (2006) Ion chromatographic determination of fluorine and chlorine in silicate rocks following alkaline fusion. Geostand. Geoanal. Res. 30, 121-129.

Straub, S. M. and Layne, G. D. (2003) The systematics of chlorine, fluorine, and water in Izu arc front volcanic rocks: Implications for volatile recycling in subduction zones. Geochim. Cosmochim. Acta 67, 4179-4203.

Straub, S. M., Layne, G. D., Schmidt, A. and Langmuir, C. H. (2004) Volcanic glasses at the Izu arc volcanic front: New perspectives on fluid and sediment melt recycling in subduction zones. Geochem. Geophys. Geosyst. 5, doi:10.1029/ $2002 \mathrm{gc000408.}$

Ueno, Y., Ono, S., Rumble, D. and Maruyama, S. (2008) Quadruple sulfur isotope analysis of $c a$. 3.5 Ga Dresser Formation: New evidence for microbial sulfate reduction in the early Archean. Geochim. Cosmochim. Acta 72, 5675-5691.

Wang, Q. Y., Makishima, A. and Nakamura, E. (2010) Determination of fluorine and chlorine by pyrohydrolysis and ion chromatography: Comparison with alkaline fusion digestion and ion chromatography. Geostand. Geoanal. Res. 34, 175-183.

Wassenaar, L. I. and Koehler, G. (2004) On-line technique for the determination of the delta $\mathrm{Cl}-37$ of inorganic and total organic $\mathrm{Cl}$ in environmental samples. Anal. Chem. 76, 63846388. 